\title{
IN VIVO BIOCOMPATIBILITY OF APATITE-FIBER SCAFFOLD WITH ENHANCED MECHANICAL PROPERTY USING PIG MODEL BY IMPLANTING INTO TIBIA
}

\author{
T. Ganmoto ${ }^{1}$, M. Honda ${ }^{2}$, T. Konishi ${ }^{2}$, M. Mizumoto $^{2}$, H. Matsunari $^{3}$, \\ Y. Takeuchi ${ }^{3}$, H. Nagashima, ${ }^{2,3}$ and M. Aizawa ${ }^{1}$ *
}

(*Corresponding author: mamorua@isc.meiji.ac.jp)

\footnotetext{
${ }^{1}$ Meiji University / Department of Applied Chemistry, School of Science and Technology,

1-1-1 Higashimita, Tama-ku, Kawasaki, 214-8571, Japan

${ }^{2}$ Kanagawa Academy of Science and Technology (KAST) / 3-2-1 Sakado, Takatsu-ku, Kawasaki, 213-0012, Japan

${ }^{3}$ Meiji University / Department of Biological Science, School of Agriculture, 1-1-1 Higashimita, Tama-ku, Kawasaki, 214-8571, Japan
}

Keywords: Apatite fiber, Scaffold, Apatite-fiber Scaffold, Biocompatibility, In vivo evaluation

\begin{abstract}
We have successfully synthesized single-crystal apatite fibers (AF) by a homogeneous precipitation method with urea. The AF has a higher solubility than isotropic HAp powders. Thus, using the AF, we developed apatite-fiber scaffolds (AFSs) that enables three-dimensionally cell culture and induces differentiation into osteoblasts. Recently, we have successfully enhanced mechanical properties of the AFSs using carbon beads (CB) with a diameter of $150 \mu \mathrm{m}$ and $20 \mu \mathrm{m}$, together with uniaxial pressing of the green compacts. In this study, we fabricated the AFSs with enhanced mechanical property (AFS700(50-50)), and then implanted them into tibia of pig to evaluate a biocompatibility to a hard tissue. The porosity of the resulting and compressive strength of typical AFS700(50-50) were $93.5 \%$ and $128 \mathrm{kPa}$, respectively. The AFS700(50-50) had a number of micro pores, macro-pores and interconnected pores. In the histological observation after 13 weeks implantation, newly-formed bone and cells were invaded into pores of the AFS700(50-50), and the scaffolds were incorporated into a cycle of bone remodeling. The AFS700(50-50) was also observed to be replaced with autologous tissue. The present scaffold may be expected as a high performance scaffold for bone regeneration.
\end{abstract}

(Received May 8, 2012; Accepted May 16, 2012)

\section{INTRODUCTION}

Tissue engineering is one of the most important technologies that regenerate the defected tissues utilizing scaffolds, cells and growth factors. In general, porous bioceramics, such as hydroxyapatite $\left(\mathrm{Ca}_{10}\left(\mathrm{PO}_{4}\right)_{6}(\mathrm{OH})_{2} ; \mathrm{HAp}\right)$, due to the similarity to bone mineral in composition, have been used as a scaffold for bone tissue regeneration. Many researchers are trying to develop high-performance scaffolds made of calcium phosphates with high porosity, interconnected pores, and excellent biocompatibility $[1,2]$.

The HAp is known to have two different crystallographic $a$ - and $c$-planes. We have successfully synthesized single-crystal apatite fibers (AF) by a homogeneous precipitation method with urea [3]. The AF has a higher solubility than isotropic HAp powders [4]. Thus, using the AF, we developed apatite-fiber scaffolds (AFSs) that enables three-dimensionally cell culture and induces differentiation into osteoblasts [2]. Recently, we have successfully enhanced mechanical properties of the AFSs using carbon beads (CB) with a diameter of $150 \mu \mathrm{m}$ and $20 \mu \mathrm{m}$ [5], together with uniaxial pressing of the green compacts.

In this study, the AFSs with enhanced mechanical property were implanted into tibia of pig, and examined the biocompatibility to a hard tissue.

\section{MATERIALS AND METHODS}

The AF was synthesized via a homogeneous precipitation method using urea [3]. An AF slurry was prepared by admixing 1 mass\% volume fraction of $\mathrm{AF}$ to the mixture fluid (ethanol/water $=1 / 1(\mathrm{v} / \mathrm{v})$ ). Spherical CBs (diameter $150 \mu \mathrm{m}$ and $20 \mu \mathrm{m}$ ) were added to the AF slurry in the $A F / C B(w / w)$ ratio of $1 / 7$ ( $\mathrm{AF} / \mathrm{CB}$ slurry). After the $\mathrm{AF} / \mathrm{CB}$ slurry was 
Table 1 Fabrication of AFSs and some properties

\begin{tabular}{ccccc}
\hline Sample & $\begin{array}{c}150 \mu \mathrm{mCB}[\mathrm{g}] / \\
\mathrm{AF} 1 \mathrm{~g}\end{array}$ & $\begin{array}{c}20 \mu \mathrm{mCB}[\mathrm{g}] / \\
\mathrm{AF} 1 \mathrm{~g}\end{array}$ & $\begin{array}{c}\text { Porosity } \\
{[\%]}\end{array}$ & $\begin{array}{c}\text { Compressive strength } \\
{[\mathrm{kPa}]}\end{array}$ \\
\hline AFS700(0-100) & 0 & 7 & 92.5 & 71 \\
AFS700(50-50) & 3.5 & 3.5 & 93.5 & 128 \\
AFS700(100-0) & 7 & 0 & 95.0 & 52 \\
\hline
\end{tabular}

stirred and blended homogeneously, green compacts for the scaffold were fabricated by pouring and vacuum pumping the slurry into the metallic mold of $4.2 \mathrm{~mm}$ in internal diameter. Compacts inside the mold were uniaxial pressed at $30 \mathrm{MPa}$ and fired at $1300{ }^{\circ} \mathrm{C}$ for $5 \mathrm{~h}$ in a steam atmosphere to fabricate the AFSs with enhanced mechanical property. We fabricated three types of AFSs with different porous structure, and named the resulting scaffolds "AFS700 (150 $\mu \mathrm{m}$ CB [mass\%] - $20 \mu \mathrm{m} \mathrm{CB}$ [mass\%])" as given in Table1.

The resulting scaffolds were characterized by X-ray diffractometry (XRD), Fourier-transform infrared spectrometry (FT-IR), and scanning electron microscopy (SEM).

Three types of AFSs were implanted into tibia of pig for periods of 13 weeks, and examined the biocompatibility to a hard tissue on the basis of histological evaluations.

\section{RESULTS AND DISCUSSION}

Figure 1 shows the XRD patterns of the resulting AFSs. The resulting scaffolds were single-phase apatite in all the fabrication conditions. The porosity and compaction strength of the resulting AFSs were given in Table 1 . The porosity of the AFSs was in the range of 92.5 to $95 \%$, and the compaction strength attained maximum $128 \mathrm{kPa}$ among examined specimens.

Scanning electron microscopy (SEM) observation of the resulting AFSs showed their porous structure (Fig. 2). In the AFS700(0-100) (Fig. 2a) and AFS700(100-0) (Fig. 2b), macro-pores derived from each $\mathrm{CB}$ (diameter $150 \mu \mathrm{m}$ or $20 \mu \mathrm{m}$ ) were observed, together with the micro-pores due to intertwining of the individual AFs. In the AFS700(50-50) (Fig. 2c), two types of macro pores of different diameters were present; furthermore, a number of interconnected pores were observed as shown in Fig. 2d. The micro pores can successfully trap osteogenic cells and osteogenic proteins such as BMPs, and the macro pores and interconnected pores enable bone tissue and osteogenic cells to invade.

Figure 3 shows the results of histological evaluation of the resulting AFSs. Histological observation by toluidine blue staining showed that bone tissue and cells well invaded into the pores in the AFSs. Furthermore, bone tissue was directly connected with the pore surface of the AFSs, and most of them in the AFSs were matured. No pathological calcifications were observed in any of the histological sections. In the AFS700(100-0), the original porous structure was preserved. In the AFS700(0-100) and AFS700(50-50), parts of the AFS were resorbed to replace with newly-formed bone.

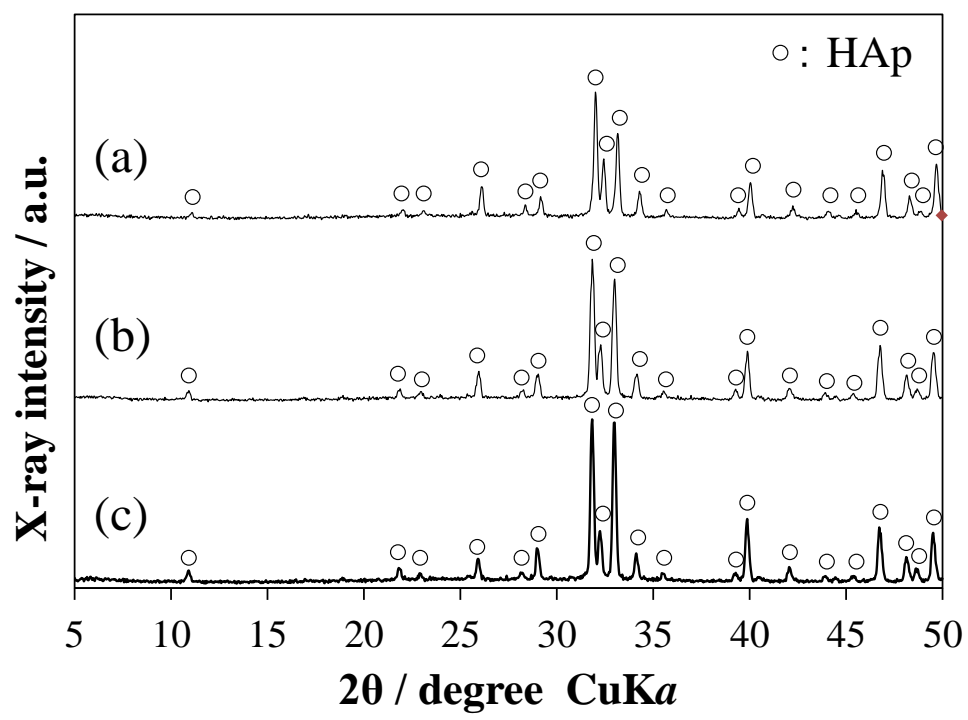

Fig. 1 XRD patternes of the AFSs: (a)AFS700(0-100), (b)AFS700(50-50), and (c)AFS700(100-0). 


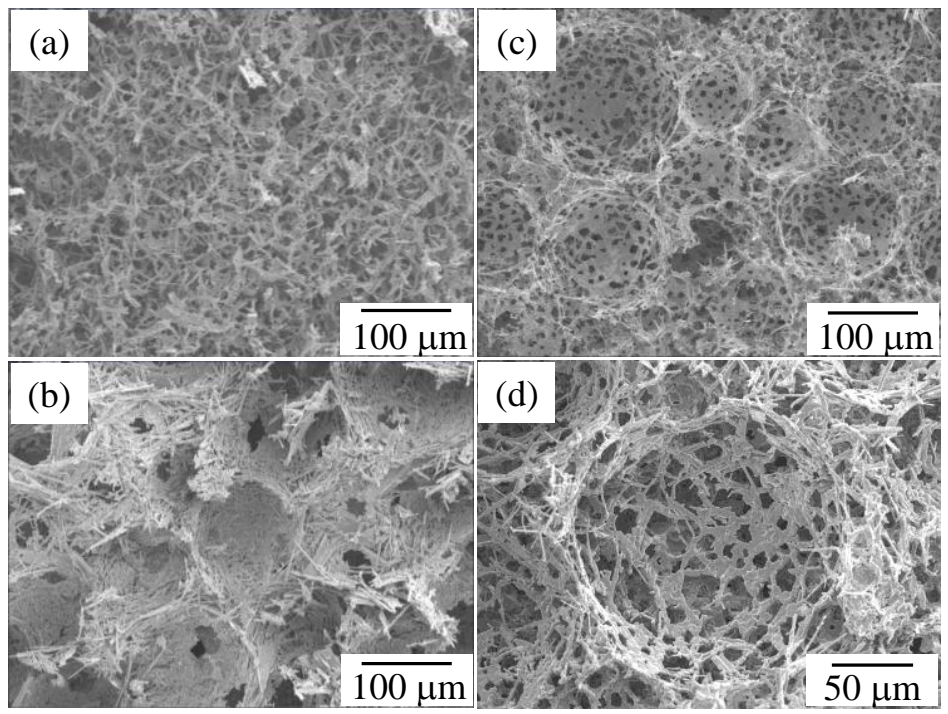

Fig. 2 SEM observation of the AFSs: (a) AFS700(0-100), (b) AFS700(100-0), (c) AFS700(50-50), and (d) high-magnification image of (c).
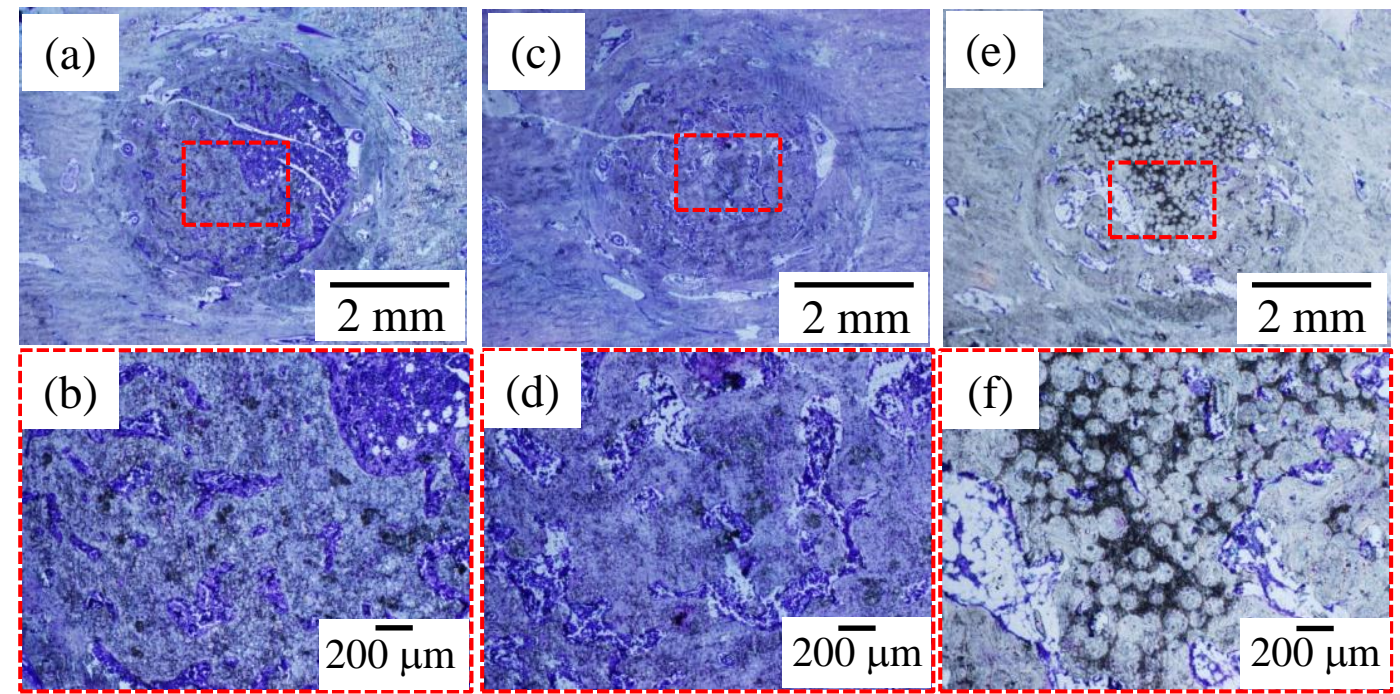

Fig. 3 Histological evaluation of the resulting AFSs: (a, b) AFS700(0-100), (c, d) AFS700(50-50), and (e, f) AFS700(100-0).

\section{CONCLUSIONS}

The porosity of the resulting AFSs was 92\% over. The compressive strength of AFS700(50-50) was the highest among three types of AFSs. The AFS700(50-50) had a number of micro pores, macro-pores and interconnected pores. In the histological observation after 13 weeks implantation, the AFS700(50-50) was good to invade of host hard tissue and cells, and observed to be replaced with autologous tissue. Therefore, the AFS700 (50-50) may be expected as a high performance scaffold.

\section{REFERENCE}

1. N. Tamai, A. Myoui, T. Tomita, T. Nakase, J. Tanaka, T. Ohchi and H. Yoshikawa, J. Biomed. Mater Res., 59, pp. 110-117(2002).

2. M. Aizawa, H. Shinoda, H. Uchida, I. Okada, T.J. Fujimi, N. Kanzawa, H. Morisue, M. Matsumoto and Y. Toyama, Phosphorus Res. Bull., 17, pp. 268-273(2004).

3. M. Aizawa, A.E. Porter, S.M. Best and W. Bonfield, Biomaterials, 26, pp. 3427-3433(2005).

4. H. Tanabe, A. Ohbuchi, T. Nakamura and M. Aizawa, Arch. BioCeram. Res., 6, pp. 236-239(2006). 5. S. Motojima, H. Morisue, M. Matsumoto, Y. Toyama and M. Aizawa, Bioceramics, 22, pp. 177-180(2009). 